\title{
Making (Implicit) Security Requirements Explicit for Cyber-Physical Systems: A Maritime Use Case Security Analysis ${ }^{\star}$
}

\author{
Tope Omitola ${ }^{1}$, Abdolbaghi Rezazadeh ${ }^{1}$, and Michael Butler ${ }^{1}$ \\ Cyber-Physical Systems Research Group, \\ Electronics and Computer Science, \\ University of Southampton \\ $\{$ tobo,ra3,mjb\}@ecs.soton.ac.uk
}

\begin{abstract}
The increased connectivity of critical maritime infrastructure (CMI) systems to digital networks have raised concerns of their vulnerability to cyber attacks. As less emphasis has been placed, todate, on ensuring security of cyber-physical maritime systems, mitigating these cyber attacks will require the design and engineering of secure maritime infrastructure systems. Systems theory has been shown to provide the foundation for a disciplined approach to engineering secure cyber-physical systems. In this paper, we use systems theory, and concepts adapted from safety analysis, to develop a systematic mechanism for analysing the security functionalities of assets' interactions in the maritime domain. We use the theory to guide us to discern the system's requirement, likely system losses, potential threats, and to construct system constraints needed to inhibit or mitigate these threats. Our analyses can be used as springboards to a set of principles to help enunciate the assumptions and system-level security requirements useful as the bases for systems' security validation and verification.
\end{abstract}

Keywords: Maritime security - Systems theory - System Theoretic Process Analysis (STPA) · Threat analysis · Cyber-Physical System Security

\section{Introduction}

With over 80 per cent of global trade by volume and more than 70 per cent of its value being carried on board ships and handled by seaports worldwide [1], the importance of a well-functioning national maritime industry cannot be over-emphasised. As key nodes in global transport chains providing access to markets, supporting supply chains, and linking consumers and producers, global

* This work has been conducted within the ENABLE-S3 project that has received funding from the ECSEL Joint Undertaking under Grant Agreement no. 692455. 
ports are under constant pressure to adapt to changes in the economic, institutional, regulatory and operating landscape. Many studies, e.g. [2], have identified maritime infrastructure and vessels to be potentially vulnerable to interference from cyber-threats. This potential vulnerability stems from a combination of increased connectivity and reliance on digital components, globally accessible navigation systems, and increasing levels of autonomous control. All such attacks have safety repercussions, with potentially serious impacts on human life, the environment and the economy. In this paper, we investigate how systems theory can be used for security requirements elicitation and analysis of an exemplar cyber-physical system (CPS), i.e., the communication systems enabling the interactions between maritime ships and their control centres.

\section{Related Work on Security Analyses of Maritime Communication System}

Due to their importance, safety and security impose constraining requirements that need to be fulfilled in the design and implementation of the communication systems of maritime assets. Maritime communication systems (MCS), as exemplar cyber-physical systems, have a coupling between the computational and physical elements, and correct system behaviour depends on correct functioning of the "interaction" of control logic with the physical system dynamics. Engineering such complex cyber-physical systems requires a holistic view on both product and process, where safety and security need to be incorporated across the engineering life-cycle to ensure such systems are safe from hazards and accidents, and secure from intentional and unintentional threats.

Traditional security analysis methods, such as THROP [6], work with threat models that are based on the fault-error-failure chain model. While these models are valid to describe threats to isolated components, they are insufficient to describe system threats in complex interconnected systems, as we have in modern CPS. STRIDE [7] takes a threat-centric approach to security analysis associating each threat with a particular asset from attackers' perspective. Although an advantage of STRIDE is that it helps change a designer's focus from the identification of specific attacks to focusing on the end results of possible attacks, one major disadvantage is that it mainly targets software systems.

In security, there can be a tendency to consider the assurance of security to be one of simply applying one particular solution, e.g. authentication or cryptography, or adhering to a best practice, such as threat modelling. But systems security, like safety and other system quality properties, is an emergent property of a system. This means that system security results from many things coming together to produce a state or condition that is free from asset loss, and the resulting loss consequences. 


\section{System Theoretic Process Analysis for Safety and Security Analysis}

System Theoretic Process Analysis (STPA) [3] is an accident causality model based on systems theory, expanding the traditional model of causality beyond a chain of directly-related failure events or component failures to include more complex processes and unsafe interactions among system components. It is based on the three concepts of (a) safety constraints, (b) a hierarchical safety control structure, and (c) process models. STPA considers events leading to accidents occur because safety constraints were not successfully enforced.

STPA performs system safety hazard analyses, while our work focusses on system security. To some extent, system safety and security can be viewed as analogues of each other. Whilst system safety, and STPA in particular, focusses on analysing the system for potential accidents and identifying the hazards that could lead to those accidents, system security considers potential losses to the system and the associated threats that could lead to those losses, so that security constraints and mechanisms can be identified and integrated into the design to address the causes of these potential threats and to reduce the risk associated with the potential losses.

STPA has the following seven steps: (1) Stating system purpose, (2) Identifying accidents, (3) Identifying system hazards associated with accidents, (4) Constructing high-level control structure, (5) Translating system hazards into high-level safety requirements, (6) Identifying unsafe control actions, and (7) Using the results to create or improve system design.

Applying STPA concepts to security analysis, we have focussed on identifying losses (instead of accidents), threats (instead of hazards), translating the threats to a set of security constraints (instead of safety requirements), and identifying insecure actions (instead of unsafe control actions).

Figure 1 shows the entities of interest of our analysis, the MCS between an SBB controller and a Ship that the SBB controls. The first step in STPA is identifying the system's purpose.

\subsection{System Purpose}

Identifying the system purpose may require a few iterations, by the security analysis team, of what the system is supposed to achieve. After doing this, we identified the purpose of the MCS to be: "the provision of timely, confidential, and correct communication of navigation data, acknowledgements and route updates, between SBB and Ship". As our focus is on the MCS, we have made use of the two primitives of SEND and RECEIVE to model the actions of data being sent and received. The next stage is to identify the losses to the system. We start by defining what a loss is. 


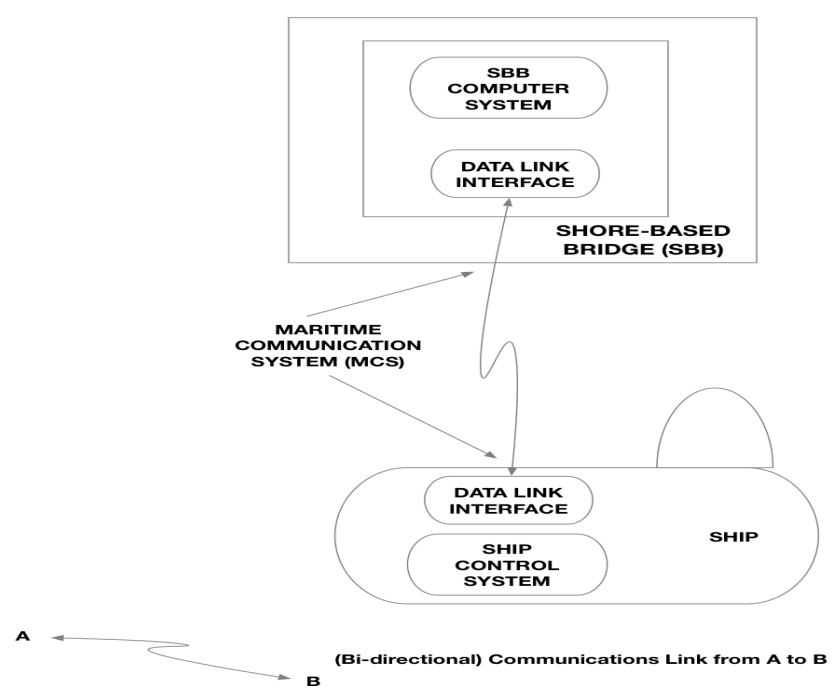

Fig. 1. Entities of Interest (MCS, SBB, and Ship)

\subsection{System Losses}

A loss is a circumstance, event or operation that can adversely impact, and/or cause failure to, a system's purpose. We can see from Section 3.1 that unauthorised reading and modification of data, as well as any operation that can affect timely data reception will adversely affect our system's purpose. Taking these into consideration, the system losses, from the points of view of both the Ship and SBB, are listed in Table 1. From Table 1, we see the correspondence between a loss, such as "Receiving Incorrect Ship Location data" $\left(L_{2}\right)$, and its impact on one of the items of the purpose statement, i.e. "correctness". The next stage in STPA is to identify the system threats.

Table 1. System Losses

\begin{tabular}{|l|l||l|l|}
\hline Loss & $\begin{array}{l}\text { Description of Loss (from SBB's } \\
\text { perspective) }\end{array}$ & Loss & $\begin{array}{l}\text { Description of Loss (from Ship's } \\
\text { perspective) }\end{array}$ \\
\hline $\mathbf{L}_{1}$ & $\begin{array}{l}\text { Not receiving ship location data (at } \\
\text { set periodic times) }\end{array}$ & $\mathbf{L}_{5}$ & $\begin{array}{l}\text { Not receiving Navigation data from } \\
\text { SBB }\end{array}$ \\
\hline $\mathbf{L}_{2}$ & $\begin{array}{l}\text { Receiving Incorrect Ship Location } \\
\text { data }\end{array}$ & $\mathbf{L}_{6}$ & $\begin{array}{l}\text { Receiving Incorrect navigation data } \\
\text { from SBB }\end{array}$ \\
\hline $\mathbf{L}_{3}$ & $\begin{array}{l}\text { Receiving Ship location/status data } \\
\text { very late }\end{array}$ & $\mathbf{L}_{7}$ & $\begin{array}{l}\text { Receiving Navigation data very late } \\
\text { from SBB }\end{array}$ \\
\hline $\mathbf{L}_{4}$ & $\begin{array}{l}\text { Un-authorised agent able to read } \\
\text { Ship location/status data sent by } \\
\text { Ship to SBB }\end{array}$ & $\mathbf{L}_{8}$ & $\begin{array}{l}\text { Un-authorised agent able to read } \\
\text { Navigation data sent by SBB to } \\
\text { Ship }\end{array}$ \\
\hline
\end{tabular}


Table 2. Possible System Threats

\begin{tabular}{|c|c|c|c|}
\hline Threat & Threat Definition & Threat & Threat Definition \\
\hline \begin{tabular}{|l|}
$\mathbf{T}_{1}$ Message \\
Congestion
\end{tabular} & $\begin{array}{l}\text { Overload of the } \\
\text { communication system } \\
\text { persisting for a time } \\
\text { significantly longer than } \\
\text { service time }\end{array}$ & $\begin{array}{l}\mathbf{T}_{2} \\
\text { Interference }\end{array}$ & $\begin{array}{l}\text { Unauthorised signal } \\
\text { disruption }\end{array}$ \\
\hline $\begin{array}{l}\mathbf{T}_{3} \\
\text { Tampering }\end{array}$ & $\begin{array}{l}\text { Unauthorised data } \\
\text { modification }\end{array}$ & $\begin{array}{l}\mathbf{T}_{4} \\
\text { Injection } \\
\text { Attack }\end{array}$ & Introduction of false messages \\
\hline $\begin{array}{l}\mathbf{T}_{5} \text { Replay } \\
\text { Attack }\end{array}$ & $\begin{array}{l}\text { Valid communication is } \\
\text { maliciously repeated or } \\
\text { delayed }\end{array}$ & $\begin{array}{l}\mathbf{T}_{6} \text { Relay } \\
\text { Attack }\end{array}$ & $\begin{array}{l}\text { Man-in-the-middle attack } \\
\text { where all messages are } \\
\text { forwarded verbatim between a } \\
\text { valid sender and a valid } \\
\text { receiver }\end{array}$ \\
\hline $\begin{array}{l}\mathbf{T}_{7} \text { Identity } \\
\text { Spoofing }\end{array}$ & $\begin{array}{l}\text { Accessing a system } \\
\text { disguised as a different } \\
\text { actor }\end{array}$ & $\begin{array}{l}\mathbf{T}_{8} \text { Loss of } \\
\text { Communi- } \\
\text { cations } \\
\text { Infrastru- } \\
\text { cture }\end{array}$ & $\begin{array}{l}\text { Unavailability of } \\
\text { communication provisioning }\end{array}$ \\
\hline $\begin{array}{l}\mathbf{T}_{9} \text { Denial of } \\
\text { Service } \\
\text { Attack } \\
\end{array}$ & $\begin{array}{l}\text { Denial of Service Attack } \\
\text { definition }\end{array}$ & $\begin{array}{l}\mathbf{T}_{10} \text { Traffic } \\
\text { Analysis }\end{array}$ & $\begin{array}{l}\text { Unauthorised study of } \\
\text { communication patterns } \\
\text { between Ship and SBB }\end{array}$ \\
\hline $\begin{array}{l}\mathbf{T}_{11} \text { Eaves- } \\
\text { dropping }\end{array}$ & $\begin{array}{l}\text { Unauthorised listening to } \\
\text { or reading of Ship and/or } \\
\text { SBB's data and } \\
\text { communication }\end{array}$ & & \\
\hline
\end{tabular}

\subsection{System Threats}

For the MCS to be effectively protected, we must resolve the security challenges inherent to that protection. These challenges can be looked at from the lens of the Confidentiality, Integrity and Availability, (C-I-A), triad. A loss of availability is the loss of the ability to access network resources. A loss of integrity is the intentional or unintentional changes to transmitted and stored data, while a loss of confidentiality is the unauthorised disclosure of transmitted and stored data.

A threat is a system state or a set of conditions that will lead to a system loss [3]. Table 2 shows the potential threats we identified for the MCS. These threats refer to specific opportunities by adversaries to defeat the system purpose and/or engender system losses. Table 3 shows the connection between threats and the losses they may cause, with a threat leading to more than one loss (e.g. $T_{1}$ being a causation factor to losses $L_{1}, L_{3}, L_{5}$ and $L_{7}$ ), or interactions of threats leading to a particular type of system loss (e.g. $T_{1}, T_{4}, T_{8}$, and $T_{9}$ as contributing factors to $\left.L_{1}\right)$. 
Table 3. System Losses And Threats

\begin{tabular}{|l|l|l|l|l|l|l|l|l|}
\hline $\begin{array}{l}\text { Losses } \\
\text { Q } \\
\text { Threats }\end{array}$ & $\mathbf{L}_{1}$ & $\mathbf{L}_{2}$ & $\mathbf{L}_{3}$ & $\mathbf{L}_{4}$ & $\mathbf{L}_{5}$ & $\mathbf{L}_{6}$ & $\mathbf{L}_{7}$ & $\mathbf{L}_{8}$ \\
\hline $\mathbf{T}_{1}$ & $\mathrm{X}$ & & $\mathrm{X}$ & & $\mathrm{X}$ & & $\mathrm{X}$ & \\
\hline $\mathbf{T}_{2}$ & & $\mathrm{X}$ & $\mathrm{X}$ & $\mathrm{X}$ & & $\mathrm{X}$ & $\mathrm{X}$ & $\mathrm{X}$ \\
\hline $\mathbf{T}_{3}$ & & $\mathrm{X}$ & & & & $\mathrm{X}$ & & \\
\hline $\mathbf{T}_{4}$ & $\mathrm{X}$ & $\mathrm{X}$ & $\mathrm{X}$ & & $\mathrm{X}$ & $\mathrm{X}$ & $\mathrm{X}$ & \\
\hline $\mathbf{T}_{5}$ & & $\mathrm{X}$ & & $\mathrm{X}$ & & $\mathrm{X}$ & & $\mathrm{X}$ \\
\hline $\mathbf{T}_{6}$ & & & & $\mathrm{X}$ & & & & $\mathrm{X}$ \\
\hline $\mathbf{T}_{7}$ & & & & $\mathrm{X}$ & & & & $\mathrm{X}$ \\
\hline $\mathbf{T}_{8}$ & $\mathrm{X}$ & & $\mathrm{X}$ & & $\mathrm{X}$ & & $\mathrm{X}$ & \\
\hline $\mathbf{T}_{9}$ & $\mathrm{X}$ & & $\mathrm{X}$ & & $\mathrm{X}$ & & $\mathrm{X}$ & \\
\hline $\mathbf{T}_{10}$ & & & & $\mathrm{X}$ & & & & $\mathrm{X}$ \\
\hline $\mathbf{T}_{11}$ & & & & $\mathrm{X}$ & & & & $\mathrm{X}$ \\
\hline
\end{tabular}

\subsection{System Control Structure}

The control structure captures functional relationships and interactions of the main components of the MCS, as a set of command actions and feedback loops. The questions to ask when constructing the control structure are: what are the main components in the system, what role does each play, and what are the command actions being used to interact. Figure 2 shows the control structures of the secure (Figure 2A) and insecure (Figure 2B) interactions between SBB and Ship.

\subsection{Defining High-level security constraints}

After identifying the threats and constructing the control structures, the next major goal is to identify the security-related constraints necessary to prevent the threats from occurring. The question STPA enabled us to ask to help us identify the constraints was: "What constraints need to be in place to prevent the aforementioned threat conditions from occurring"? The constraints we identified are listed in (Table 4).

The security constraints together with the control structure helped us to answer questions such as: (a) what are we controlling (in the case of the MCS, it is data communication security between SBB and Ship), (b) what happens when the control actions go wrong (in our case, it is the likelihood that the identified threats may manifest), and (c) how can we mitigate those things we have identified can go wrong. Therefore, looking at the threats enumerated in Table 2, the security engineers can start identifying the constraints (Table 4) that need to be in place in order to mitigate those threats. For example, a threat such as "an adversary interfering in the communication between $S B B$ and Ship" $\left(\mathbf{T}_{2}\right)$, the system constraint is to guarantee against such threat occurring. 


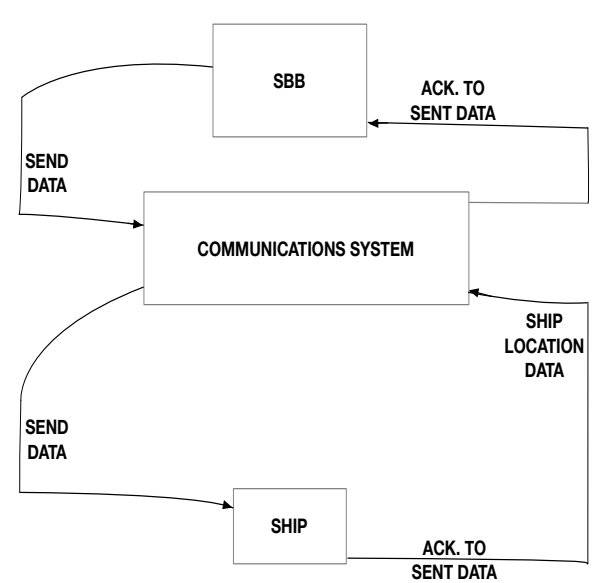

A.

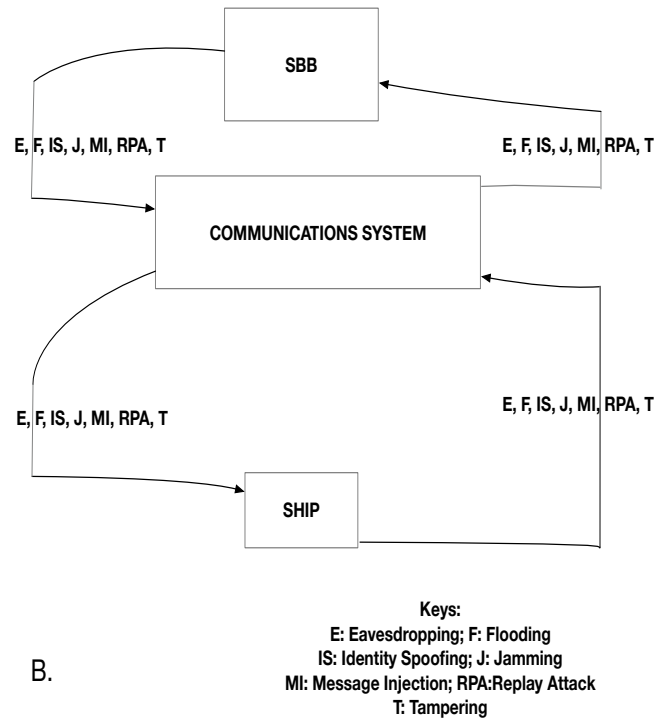

Fig. 2. Control structures for both the secure and insecure interactions between SBB and Ship

\subsection{Identifying Insecure Actions}

After the preliminary threat analyses carried out in Tables 2 and 4, the next step is to use STPA's four general categories of insecure control actions [3], to identify the conditions under which the actions of sending and receiving navigation data could lead to system threats. The security environment is dynamic, sometimes adversarial, with malicious actors that can learn how to subvert the system. In this kind of environment, the actions of interest to us are delineated as normal and malicious.

Malicious and Normal Control Actions The system's normal control actions include: the send-ing and receive-ing of navigation and acknowledgement data from both the SBB and Ship. The malicious control actions are the actions a malicious agent is likely to make that can lead to a threat. These actions include: (a) Spoofing the address resolution and the IP protocols of the underlying communication network; (b) Eavesdropping actions; as well as (c) Traffic analysis actions.

Tables 5 and 6 present our use of STPA to analyse some controls and outputs issued by the MCS. N.B. We have used the following abbreviations in the two 
Table 4. High-level Security Constraints for the MCS

\begin{tabular}{|c|c|}
\hline Threat & System Constraint \\
\hline $\begin{array}{l}\mathbf{T}_{1} \text { Communications requests exceed link } \\
\text { capacity (Message Congestion) }\end{array}$ & $\begin{array}{l}\mathbf{S C}_{1} \text { The system shall be able to prove the } \\
\text { identity of agents during transactions }\end{array}$ \\
\hline $\begin{array}{l}\mathbf{T}_{2} \text { An adversary interferes in the } \\
\text { communication between SBB and Ship } \\
\text { (Interference) }\end{array}$ & $\begin{array}{l}\mathbf{S C}_{2} \text { The system shall guarantee against } \\
\text { communication interference between SBB } \\
\text { and Ship }\end{array}$ \\
\hline $\begin{array}{l}\mathbf{T}_{3} \text { Valid communication between SBB and } \\
\text { Ship is intercepted and data are } \\
\text { maliciously modified (Tampering) }\end{array}$ & $\begin{array}{l}\mathbf{S C}_{3} \text { The system shall maintain strong } \\
\text { mutual continuous authentication, of SBB } \\
\text { and Ship, during all operations transactions }\end{array}$ \\
\hline $\begin{array}{l}\mathbf{T}_{4} \text { False messages, pretending to come } \\
\text { from a valid source, are introduced into the } \\
\text { system (Injection Attack) }\end{array}$ & $\begin{array}{l}\mathbf{S C}_{4} \text { The system shall maintain strong } \\
\text { mutual continuous authentication, of SBB } \\
\text { and Ship, during all operations' } \\
\text { transactions }\end{array}$ \\
\hline $\begin{array}{l}\mathbf{T}_{5} \text { The system maliciously repeats or } \\
\text { delays valid communication between SBB } \\
\text { and Ship (Replay Attack) }\end{array}$ & $\begin{array}{l}\mathbf{S C}_{5} \text { The system shall maintain strong } \\
\text { mutual continuous authentication, of SBB } \\
\text { and Ship, during all operations' } \\
\text { transactions }\end{array}$ \\
\hline $\begin{array}{l}\mathbf{T}_{6} \text { Valid communication is forwarded } \\
\text { verbatim between SBB and Ship by a } \\
\text { malicious agent (Relay Attack) }\end{array}$ & $\begin{array}{l}\mathbf{S C}_{6} \text { The system shall maintain strong } \\
\text { mutual continuous authentication, of SBB } \\
\text { and Ship, during all operations' } \\
\text { transactions }\end{array}$ \\
\hline $\begin{array}{l}\mathbf{T}_{7} \text { A malicious agent is pretending to be } \\
\text { the SBB, the Ship or the Communication } \\
\text { System (Identity Spoofing) }\end{array}$ & $\begin{array}{l}\mathbf{S C}_{7} \text { The system shall maintain strong } \\
\text { mutual continuous authentication, of } \\
\text { agents, during all operations transactions }\end{array}$ \\
\hline $\begin{array}{l}\mathbf{T}_{8} \text { There is discernible delay or a denial of } \\
\text { service between the SBB and Ship (Loss } \\
\text { of Communications Infrastructure) }\end{array}$ & $\begin{array}{l}\mathbf{S C}_{8} \text { The system shall detect the loss of } \\
\text { infrastructure }\end{array}$ \\
\hline $\begin{array}{l}\mathbf{T}_{9} \text { There is discernible delay or a denial of } \\
\text { service between the SBB and Ship (Denial } \\
\text { of Service Attack) }\end{array}$ & $\begin{array}{l}\mathbf{S C}_{9} \text { The system shall ensure and maintain } \\
\text { the specific turn-around time for each } \\
\text { requested operation }\end{array}$ \\
\hline $\begin{array}{l}\mathbf{T}_{10} \text { A malicious agent observes patterns of } \\
\text { communication traffic between SBB and } \\
\text { Ship (Traffic Analysis) }\end{array}$ & $\begin{array}{l}\mathbf{S C}_{10} \text { The system shall ensure protection } \\
\text { over all communication }\end{array}$ \\
\hline $\begin{array}{l}\mathbf{T}_{11} \text { An un-authorised agent listens into } \\
\text { communication between SBB and Ship } \\
\text { (Eavesdropping) }\end{array}$ & $\begin{array}{l}\mathbf{S C}_{11} \text { The system shall ensure that all the } \\
\text { communications are not readable by any } \\
\text { un-authorised party }\end{array}$ \\
\hline
\end{tabular}

tables(T: Tampering, I: Interference, IA: Injection Attack, RPA: Replay Attack, RLA: Relay Attack, IS: Identity Spoofing, DoS: DoS Attack, TA: Traffic Analysis, E: Eavesdropping).

We found that the effect of the normal actions is binary: either they leave the system fool-proof or vulnerable to all of the threats described in Section 3.3, while the malicious actions expose the system to all of these security threats. This may be due to the existence of an operational communication system exposes it to such threats. In addition, our choice of primitives of SEND and RECEIVE 
Table 5. Normal Control Actions of the MCS

\begin{tabular}{|l|l|l|l|l|}
\hline $\begin{array}{l}\text { Normal Con- } \\
\text { trol Action }\end{array}$ & $\begin{array}{l}\text { Not } \\
\text { Providing } \\
\text { Exposes } \\
\text { System } \\
\text { to } \\
\text { Threats }\end{array}$ & $\begin{array}{l}\text { Providing } \\
\text { Exposes } \\
\text { System to } \\
\text { Threats }\end{array}$ & $\begin{array}{l}\text { Wrong Time } \\
\text { or Wrong } \\
\text { Order Exposes } \\
\text { System to } \\
\text { Threats }\end{array}$ & $\begin{array}{l}\text { Stoped Too } \\
\text { Soon or Applied } \\
\text { Too Long Ex- } \\
\text { poses System to } \\
\text { Threats }\end{array}$ \\
\hline $\begin{array}{l}\text { SBB Sends Nav- } \\
\text { igation Data to } \\
\text { Ship }\end{array}$ & $\begin{array}{l}\text { UCA1 } \\
\text { IA, RPA, } \\
\text { RLA, IS, } \\
\text { DoS, TA, E }\end{array}$ & As in UCA1 & As in UCA1 \\
\hline $\begin{array}{l}\text { Ship receives } \\
\text { Navigation data }\end{array}$ & None & As in UCA1 & As in UCA1 & As in UCA1 \\
\hline $\begin{array}{l}\text { Ship sends Ack } \\
\text { to SBB }\end{array}$ & None & As in UCA1 & As in UCA1 & As in UCA1 \\
\hline $\begin{array}{l}\text { SBB receives Ack } \\
\text { data from Ship }\end{array}$ & None & As in UCA1 & As in UCA1 & As in UCA1 \\
\hline
\end{tabular}

are at a level that these states are binary, either a message is sent or not, and if a message is not sent, then no security threat arises.

\subsection{Use Results to Create or Improve Design}

The next step in STPA is to use the results of the analyses to help in designing a more secure system. Security is about risk management, and a purpose of risk management is to reduce losses. The C-I-A triad conjoined with the system losses and threats (Table 3) and with the high-level security requirements (Table 4) can help in assessing risk and weighting value. Depending on one's application domain, one can assign different values to the threats in Tables 3 and 4.

\section{Conclusions and Future Work}

This paper showed how systems theory and concepts from safety analyses, especially STPA, can be applied to the security analysis of a critical maritime infrastructure system (an exemplar cyber-physical system). We showed how STPA's systematic approach can help in eliciting the appropriate system's purpose, and to identify the losses and threats that may severely impact that purpose. We also showed how to derive the system constraints that can be used to inhibit or mitigate these threats, and described appropriate mitigation techniques.

For future work, we shall employ the Event-B [5] modelling methodology to help verify the completeness of the system constraints to mitigate or inhibit the threats that generated them. 
Table 6. Malicious Control Actions of the MCS

\begin{tabular}{|c|c|c|c|c|}
\hline $\begin{array}{l}\text { Malicious } \\
\text { Control } \\
\text { Action }\end{array}$ & $\begin{array}{l}\text { Not Providing } \\
\text { Exposes } \\
\text { the System } \\
\text { to Threats }\end{array}$ & $\begin{array}{l}\text { Providing } \\
\text { Exposes the } \\
\text { System to } \\
\text { Threats }\end{array}$ & $\begin{array}{l}\text { Wrong Time } \\
\text { or Wrong } \\
\text { Order } \\
\text { Exposes the } \\
\text { System to } \\
\text { Threats }\end{array}$ & \begin{tabular}{|lr} 
Stopped & Too \\
Soon or & Ap- \\
plied Too Long \\
Exposes & the \\
System & to \\
Threats &
\end{tabular} \\
\hline $\begin{array}{l}\text { Address } \\
\text { Resolution } \\
\text { Protocol (ARP) } \\
\text { spoofing } \\
\text { command }\end{array}$ & None & $\begin{array}{l}\text { UCA2. IS, T, } \\
\text { RPA, RLA, IA }\end{array}$ & As in UCA2 & As in UCA2 \\
\hline $\begin{array}{l}\text { IP spoofing } \\
\text { command }\end{array}$ & None & As in UCA2 & As in UCA2 & As in UCA2 \\
\hline $\begin{array}{l}\text { Packet } \\
\text { Tampering } \\
\text { command }\end{array}$ & None & As in UCA2 & As in UCA2 & As in UCA2 \\
\hline $\begin{array}{l}\text { Eavesdropping } \\
\text { command } \\
\text { (e.g. via a } \\
\text { Network sniffer) }\end{array}$ & None & $\begin{array}{l}\text { UCA3. Eaves- } \\
\text { dropping. Usu- } \\
\text { ally a passive } \\
\text { attack }\end{array}$ & As in UCA3 & As in UCA3 \\
\hline 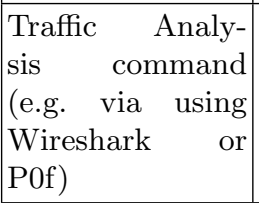 & None & $\begin{array}{l}\text { UCA4. Traffic } \\
\text { Analysis. Nor- } \\
\text { mally a passive } \\
\text { attack }\end{array}$ & As in UCA4 & As in UCA4 \\
\hline
\end{tabular}

\section{References}

1. United States Navy Biography: http://www.navy.mil/navydata/leadership/ quotes.asp? $\mathrm{q}=253 \& \mathrm{c}=6$ Last accessed 28 November 2018

2. UK Cabinet Office: "National Cyber Security Strategy 2016 to 2021", UK Cabinet Office, Nov. 2016

3. Leveson, N.G., Thomas, J.P.: "STPA Handbook", pub. 2018

4. Howard, G., Butler, M., Colley, J., Sassone, V.: Formal Analysis of Safety and Security Requirements of Critical Systems Supported by an Extended STPA Methodology. In: 2nd Workshop on Safety \& Security aSSurance. https://doi.org/10.1109/EuroSPW.2017.68 2017

5. Abrial, J.-R.: Modeling in Event-B: System and Software Engineering. pub. Cambridge University Press, 2010

6. Durrwang, J., Beckers, K., Kriesten, R.: A Lightweight Threat Analysis Approach Intertwining Safety and Security for the Automotive Domain. https://doi.org/10.1007/978-3-319-66266-4_20 2017

7. Potter, B.: Microsoft SDL Threat Modelling Tool. In: Network Security 2009 vol. 1, pp. 15-18, 2009 